\title{
Pengaruh Social Media dan Brand Image Terhadap Purchase Decision Melalui Buying Interest
}

\author{
Sutiyati $^{1}$, Henny Welsa ${ }^{2}$, Ambar Lukitaningsih $^{3}$ \\ ${ }^{1}$ Universitas Sarjanawiyata Tamansiswa, uthiemoeslimah@gmail.com \\ ${ }^{2}$ Universitas Sarjanawiyata Tamansiswa, henny_welsa@yahoo.com \\ ${ }^{3}$ Universitas Sarjanawiyata Tamansiswa, ambaryudono@yahoo.com
}

\begin{abstract}
ABSTRAK
Penelitian ini bertujuan untuk mengetahui variabel paling berpengaruh dan penting yang menyebabkan menurunnya jumlah masyarakat yang berwisata ke pantai Parangtritis Yogyakarta sesuai dengan permasalahan yang telah dirumuskan. Ukuran sampel sebesar 97yang dapat mewakili populasi ditentukan dengan menggunakan metode Krejcie-Morgan. Metode analisis dalam penelitian ini menggunakan analisis Structural Equation Modeling (SEM) yang berbasis varians yaitu Partial Least Square (PLS). Teknik pengambilan sampel pada penelitian ini adalah accidental sampling menggunakan instrumen kuosioner. Variabel social media berpengaruh positif dan signifikan terhadap purchase decision dengan $p$ values sebesar 0.000 ; Variabel brand image berpengaruh positif dan signifikan terhadap purchase decision dengan $p$ values sebesar 0.018; Variabel social media berpengaruh positif dan signifikan terhadap buying interest dan $\mathrm{p}$ values 0.008; Variabel brand image berpengaruh positif namun tidak signifikan terhadap buying interest dengan nilai original sampel sebesar 0.213 dan nilai $\mathrm{p}$ values sebesar 0.129 . Variabel buying interest berpengaruh positif namun tidak signifikan terhadap purchase decision dibuktikan dengan data nilai original sampel sebesar 0.014 dan $\mathrm{p}$ values sebesar 0.764 ; buying interest sebagai intervening berpengaruh pada hubungan variabel social media dan purchase decision dengan nilai Zscore (2.67) > Ztabel (1.96); buying interest sebagai intervening tidak berpengaruh pada hubungan variabel brand image terhadap purchase decision dengan nilai Zscore (1.08) < Ztabel (1.96).

Kata Kunci : Social media, Brand image, buying interest, purchase decision
\end{abstract}

\begin{abstract}
The purpose of this research is to determine the most influential and important variables that cause the low totally of the peoples has been visited at Parangtritis beach Yogyakarta in accordance with the problems that have been formulated. A sample size of 97 that can represent the population is determined using the Krejcie-Morgan method. The method of analysis in this study is to use a variance-based analysis of Structural Equation Modeling (SEM), namely Partial Least Square (PLS). The sampling technique in this study is accidental sampling using a questionnaire instrument. Social media variables have a positive and significant effect on purchase decision by showing $p$ values of 0.000; brand image variable has a positive and significant effect on purchase decision with $p$ values of 0.018; social media variables has a positive and significant effect on buying interest and $p$ values of 0.008; brand image variable has a positive but not significant effect on work stress with an original sample value of 0.213 and a p value of 0.129; buying interest variables have a positive and significant effect on purchase decision as evidenced by the original sample value of 0.014 and $p$ values of 0.764; buying interest as intervening influences has effect on relationship between social media variables and purchase decision with zscore (2.67)> ztable (1.96); buying interest as an
\end{abstract}

ISSN: 2355-0295, e-ISSN: 2549-8932 264

http://ejournal.bsi.ac.id/ejurnal/index.php/ecodemica 
intervening has not effect on relationship between brand image and purchase decision with zscore $(1.08)<$ ztable (1.96).

Keywords: Social media, Brand image, buying interest, purchase decision

Naskah diterima: 27-08-2020, direvisi: 11-06-2020, diterbitkan: 01-09-2020

\section{PENDAHULUAN}

Pariwisata merupakan bagian yang tidak terpisahkan dari kehidupan manusia terutama menyangkut kegiatan sosial dan ekonomi. Indonesia sebagai negara yang sedang berkembang dalam tahap pembangunannya, berusaha membangun industri pariwisata sebagai salah satu cara untuk mencapai neraca perdagangan luar negeri yang berimbang. Melalui industri ini diharapkan pemasukan devisa dapat bertambah (Pangestu, 2018). Daerah Istimewa Yogyakarta salah satu tujuan wisata favorit bagi wisatawan, baik bagi wisatawan nusantara maupun wisatawan mancanegara. Kegiatan yang berbasis pariwisata merupakan salah satu upaya yang dilakukan pihak pemerintah untuk mempromosikan potensi wisata yang ada di DIY (Edy Susanto, 2019). Pariwisata di DIY mengalami peningkatan dari tahun ke tahun. Pantai Parangtritis merupakan objek wisata pantai andalan dan menjadi icon pariwisata di Kabupaten Bantul karena memiliki potensi yang sangat menarik dengan keindahan dan keunikan gumuk pasir menjadikan sebagai satu brand image yang unggul dan menarik bagi masyarakat yang berwisata ke pantai Parangtritis (Dejan, 2018). Potensi media sosial sebagai media promosi pariwisata sangatlah besar, akan tetapi yang menjadi permasalahan adalah bagaimana agar media sosial tersebut seperti instagram dan facebook dapat dikenal dan memiliki banyak pengikut agar konten yang dipublikasikan atau diunggah dapat diterima oleh orang banyak. Social media Instagram pantai parangtritis Jogja adalah salah satu dari instagram obyek wisata di Yogyakarta yang dibuat dengan harapan dapat meningkatkan jumlah kunjungan masyarakat yang berwisata ke Pantai Parangtritis Jogja (Daga, 2019). Jumlah kunjungan wisatawan di pantai Parangtritis mengalami penurunan pada tahun 2019. Pada tahun 2018 jumlah kunjungan di pantai Parangtritis mencapai 2,89 juta pengunjung sedangkan pada tahun
2019 jumlah kunjungan mencapai 2,81 juta pengunjung. Adanya citra merk (Brand Image) yang dimiliki oleh pantai Parangtritis Jogja, pengelola pantai Parangtritis menargetkan jumlah kunjungan meningkat pada tahun 2020 menjadi 2,95 juta pengunjung (Koesbianto, 2019). Minat sebagai dorongan, yaitu rangsangan internal yang kuat yang memotivasi tindakan, dimana dorongan ini dipengaruhi oleh stimulus dan perasaan positif akan produk. Jika rangsangan atau dorongan yang di berikan melebihi ekspektasi maka konsumen akan bisa menerima perasaan positif atau menyenangkan sehingga memiliki minat beli yang lebih kuat dan dampaknya muncul keputusan untuk membeli di bandingkan jika minat beli yang lemah konsumen akan melakukan pemilihan alternatif lain sebelum melakukan keputusan pembelian. Keputusan pembelian yang dilakukan oleh konsumen menggambarkan seberapa jauh tingkat pengaruh usaha pemasaran yang dilakukan terhadap suatu produk sehingga pemasar harus mengetahui perilaku konsumen dalam hal menentukan keputusan pembeliannya

(Nulufi \& Murwatiningsih, 2018). Melihat bahwa pentingnya peningkatan jumlah masyarakat yang berwisata, keputusan pembelian masyarakat dalam berwisata menjadi satu hal yang harus diperhatikan dalam industry pariwisata, juga berlaku pada industri pariwisata di Daerah Istimewa Yogyakarta, salah satu kota yang menjadi sasaan tujuan wisata dengan destinasi yang menarik di Indonesia. Dari banyaknya destinasi wisata di Yogyakarta, Pantai Parangtritis hadir berbeda dalam menarik minat bagi para pengunjungnya, dengan citra yang dimiliki dari masing-masing, yang mana Pantai Parangtritis sudah ada dari dahulu dan menarik bagi masyarakat yang berkunjung bukan hanya regional tetapi internasional menjadikan pantai Parangtritis memiliki citra tersendiri bagi para masyarakat lokal, nasional maupun mancanegara. 


\section{KAJIAN LITERATUR}

Deskripsi Konseptual

Media sosial didefinisikan mengacu pada semua situs web dan aplikasi yang memungkinkan orang untuk membuat dan/atau berbagi konten dan yang memberikan kesempatan untuk berpartisipasi dalam jejaring social (Meslat, 2018). Media sosial didefinisikan sebagai sebuah media online, dengan para penggunanya bisa dengan mudah berpartisipasi, berbagi, dan menciptakan isi meliputi blog, jejaring sosial, wiki, forum dan dunia virtual. Beberapa situs media sosial yang populer sekarang ini antara lain: Blog, Twitter, Facebook, Instagram, Path, dan Wikipedia (Nurkarima, 2018).

Brand Image adalah Photo-photo yang menarik dan pesan yang mampu menginspirasi dapat mempengaruhi sikap pengunjung jejaring sosial untuk menyukai jejaring sosial tersebut dan membuat jumlah pengunjung jejaring sosial bertambah (Sriyanto \& A.W., 2019). Brand Image (citra merek) adalah persepsi konsumen terhadap perusahaan atau produknya. Menurutnya, citra suatu merek tidak dapat ditanamkan di dalam pikiran pelanggan dalam waktu cepat dan melalui satu media saja, melainkan citra suatu merek harus disampaikan kepada pelanggan melalui tiap sarana komunikasi yang tersedia dan disebarkan secara terus menerus, karena tanpa citra yang kuat sangatlah sulit untuk suatu perusahaan dapat menarik pelanggan baru untuk membeli produk dari perusahaan (Alexi, Zulkarnain, \& Musfar, 2017).

Minat beli konsumen adalah sesuatu yang timbul setelah menerima rangsangan dari produk yang dilihatnya, darisana timbul timbul ketertarikan untuk mencoba produk tersebut sampai pada akhirnya timbul keinginan untuk membeli agar dapat memilikinya (Kotler, 2005). Untuk mengaktifkan minat beli ada dua hal yang sangat berperan, yaitu :

1. Ingatan konsumen akan merek produk, yang berguna sebagai rencana keputusan saat dihadapkan pada situasi pembelian.

2. Diusahakan keberadaanya, yaitu melalui pengintegrasian ketika konsumen melakukan proses keputusan pembelian, misalnya promosi.

Purchase Decision merupakan keputusan yang diambil konsumen dalam menghadapi permasalahan dengan menggunakan serta memanfaatkan segala macam informasi yang telah diketahui dan kemudian menilai dari berbagai alternatif yang dapat dipilih (Kotler \& Keller, 2016). Keputusan pembelian adalah sebuah proses dimana konsumen mengenal masalahnya, mencari informasi mengenai produk atau merek tertentu dan mengevaluasi seberapa baik masing-masing alternatif tersebut dapat memecahkan masalahnya yang kemudian mengarah kepada keputusan (Alexi et al., 2017).

\section{Deskripsi Teoretik}

Menurut (Meslat, 2018) menjelaskan bahwa purchase decision dipengaruhi secara langsung oleh social media. (Yogesh \& Yesha, 2018) menjelaskan bahwa purchase decision dipengaruhi secara langsung oleh social media juga. Dan menurut (Caecilia, Kindangen, \& Tumewu, 2017) menjelaskan bahwa purchase decision dipengaruhi secara langsung oleh social media marketing youtube dan instagram, namun social media marketing facebook berpengaruh secara tidak langsung dalam purchase decision.

Menurut (Alexi et al., 2017) menjelaskan bahwa purchase decision dan repurchase decision dipengaruhi langsung oleh brand image dan product design. (Prasetya, Yulianto, \& Sunarti, 2018) menjelaskan bahwa purchase decision dipengaruhi langsung oleh brand image. Sedangkan menurut (Rommy, Moh, \& Nur, 2018) menjelaskan bahwa purchase decision dipengaruhi secara langsung oleh brand image dan price perception. Menurut (Sudaryanto, Subagio, Awaliyah, Wulandari, \& Hanim, 2019) consumer purchase decision dipengaruhi langsung oleh brand image, price dan promotion.

(Raheni, 2018) menjelaskan bahwa minat beli konsumen dipengaruhi secara langsung oleh media social . menurut (Amalia \& Sunarti, 2019) minat berkunjung follower dipengaruhi secara langsung oleh media social instagram. 
(Romadhona, Sudapet, \& Subagio, 2018) menjelaskan bahwa consumer buying interest dipengaruhi secara langsung oleh packaging design, promotion dan brand image. (Mughoffar, Sumarwan, \& Tinaprilla, 2019)menjelaskan bahwa buying interest dipengaruhi secara langsung oleh E-wom dan brand image. Sedangkan menurut (Rommy et al., 2018) menjelaskan bahwa minat beli smart phone oppo dipengaruhi secara langsung oleh brand image.

(Rahmawati, 2018) menjelaskan bahwa keputusan pembelian konsumen shoppee dipengaruhi secara langsung oleh minat beli dan harga. Menurut (Montjai, Tewal, \& Lengkong, 2018) menjelaskan bahwa keputusan pembelian sepeda motor Yamaha dipengaruhi secara langsung oleh motivasi, sikap dan minat beli konsumen. Sedangkan (Sriyanto \& A.W., 2019) menjelaskan bahwa keputusan pembelian online shop di Shopee dipengaruhi secara langsung oleh brand ambassador, minat beli dan testimoni.

(Putri, 2018) menjelaskan bahwa keputusan pembelian konsumen Cherie dipengaruhi secara tidak langsung oleh social media melalui minat beli. Menurut (Kurniasari \& Budiatmo, 2018) menjelaskan bahwa keputusan pembelian J.Co donuts \& Coffee Semarang dipengaruhi secara tidak langsung oleh social media marketing dan brand awareness melalui minat beli. (Haikal \& Suliyanto, 2018) menjelaskan bahwa purchase decision dipengaruhi secara tidak langsung oleh consumer ethnocentrism, brand image dan perceived quality melalui buying interest.

(Nulufi \& Murwatiningsih, 2018) menjelaskan bahwa keputusan pembelian batik di Pekalongan dipengaruhi secara tidak langsung oleh brand image dan sikap konsumen melalui minat beli. (Hasyyati \& Khasanah, 2019) menjelaskan bahwa keputusan pembelian produk toko sepatu Bata dipengaruhi secara tidak langsung oleh kualitas produk, persepsi harga dan citra merek melalui minat beli konsumen.

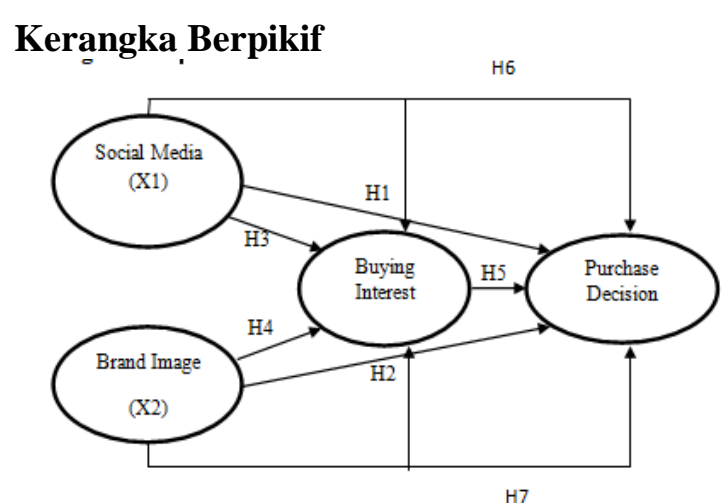

Gambar 1. Kerangka Pemikiran Penelitian

\section{METODE PENELITIAN}

\section{Pengukuran dan Pengumpulan Data}

Sebuah survei dengan teknik accidental sampling dilakukan pada masyarakat yang berwisata ke pantai Parangtritis Yogyakarta. Proses penyebaran dilakukan dengan google form melalui social media whatts app, instagram dan facebook. Masyarakat yang berwisata ke pantai Parangtritis Yogyakarta adalah target dari penelitian ini.

Instrumen untuk pengumpulan data adalah kuesioner yang terstruktur. Variabel social media menggunakan indikator yang digunakan oleh peneliti (Nurkarima, 2018) yang meliputi unsur-unsur penilaian sebagai berikut: Interest Content, Easy to acess dan Easy to understand. Pengukuran variabel brand image menggunakan indikator yang digunakan oleh peneliti (Prasetya et al., 2018) dengan unsur-unsur penilaian sebagai berikut : Daya tarik dari destinasi, Harga tiket masuk destinasi, Fasilitas dari destinasi dan Kemudahan dari destinasi. Adapun untuk indikator dari buying interest sejalan dengan yang dilakukan oleh (Pebriani, Sumarwan, \& Simanjuntak, 2018) yaitu transactional interest dan explorative interest. Sedangkan Pengukuran variabel purchase decision menggunakan indikator yang digunakan oleh peneliti (Bagus Nur Herawan, 2018) yaitu : intend to make a purchase, Habit dan Recommendation. Semua item diukur menggunakan skala Likert 5 poin $(1=$ sangat tidak setuju, 5 = sangat setuju). Demografi responden sederhana juga diterapkan pada kuesioner dengan pertanyaan mengenai jenis 
kelamin, usia, tingkat pendidikan dan rata-rata pendapatan perbulannya.

\section{Analisis Data}

Alat analisis yang digunakan dalam penelitian ini adalah Patial Least Square (PLS), yaitu SEM yang berbasis variance, dengan software SmartPLS 3.2.8. Tahapan pengujian PLS dilakukan sebagai berikut:

\section{a. Uji Indikator}

Dari uji indikator ini diperoleh output validitas dan realibilitas model yang diukur dengan kriteria: Convergent Validity, Discriminant Validity, dan Composite Reliability.

b. Uji Model Fit (Analisis Inferensial)

Pengujian model fit dilakukan untuk menguji Standardized Root Mean Square Residual (SRMSR), d_ULS (jarak Euclidean kuadrat) dan d_G (jarak geodesic, Chi-Square, NFI dan RMS Theta (Henseler, Marko, \& sarstedt, 2014).

\section{PEMBAHASAN}

\section{Karakteristik Sampel}

Sampel dikelompokan berdasarkan usia, jenis kelamin, pendidikan terakhir, dan pendapatan rata-rata perbulan.

Tabel 1. Usia Responden

\begin{tabular}{|c|l|c|c|}
\hline No & \multicolumn{1}{|c|}{ Umur } & Frekuensi & Persen \\
\hline 1 & $15-24$ tahun & 44 & 45,4 \\
\hline 2 & $25-34$ tahun & 20 & 20,6 \\
\hline 3 & $35-44$ tahun & 25 & 25,8 \\
\hline 4 & $>45$ tahun & 8 & 8,2 \\
\hline & Total & 97 & 100 \\
\hline
\end{tabular}

Sumber: Data Primer diolah

Berdasarkan tabel 1. diperoleh hasil usia responden yang berwisata ke pantai Parangtritis Yogyakarta adalah usia 15-24 tahun sebanyak 44 orang atau sebesar $45,4 \%$, usia 25-34 tahun sebanyak 20 0rang atau sebesar 20,6\%, usia 35-44 tahun sebanyak 25 orang atau sebesar $25,8 \%$ dan usia $>45$ tahun sebanyak 8 orang atau sebesar $8,2 \%$. Usia $>45$ tahun merupakan karakteristik usia responden dengan persentase paling kecil sedangkan usia 15-24 tahun merupakan karakteristik usia responden dengan persentase paling besar.

Tabel 2. Jenis Kelamin

\begin{tabular}{|c|l|c|c|}
\hline No & Jenis kelamin & Frekuensi & Persen \\
\hline 1 & Perempuan & 65 & 67 \\
\hline 2 & Laki-laki & 32 & 33 \\
\hline & Total & 97 & 100 \\
\hline
\end{tabular}

Sumber: Data Primer diolah

Berdasarkan tabel 2. diperoleh hasil bahwa responden yang berwisata ke pantai Parangtritis Yogyakarta berjenis kelamin perempuan sebanyak 65 orang atau sebesar $67 \%$, sedangkan responden berjenis kelamin laki-laki sebanyak 32 orang atau sebesar 33 $\%$.

Tabel 3. Pendidikan Terakhir

\begin{tabular}{|c|l|c|c|}
\hline No & $\begin{array}{c}\text { Pendidikan } \\
\text { Terakhir }\end{array}$ & Frekuensi & Persen \\
\hline 1 & SLTP,SLTA & 57 & 58,8 \\
\hline 2 & D III & 7 & 7,3 \\
\hline 3 & S1, S2 & 29 & 29,9 \\
\hline 4 & Lain-lain & 4 & 4 \\
\hline & Total & 97 & 100 \\
\hline
\end{tabular}

Sumber: Data Primer diolah

Berdasarkan tabel 3. diperoleh hasil pendidikan terakhir responden yang berwisata ke pantai Parangtritis Yogyakarta adalah SLTP,SLTA sebanyak 57 orang atau $58,8 \%$, D III 7 orang atau 7,3\%, S1,S2 sebanyak 29 orang atau $29,9 \%$ dan kategori lain-lain sebnayak 4 orang atau $4 \%$. Persentase paling kecil adalah jenjang pendidikan kategori lainlain sedangkan persentase paling besar adalah jenjang pendidikan SLTP, SLTA.

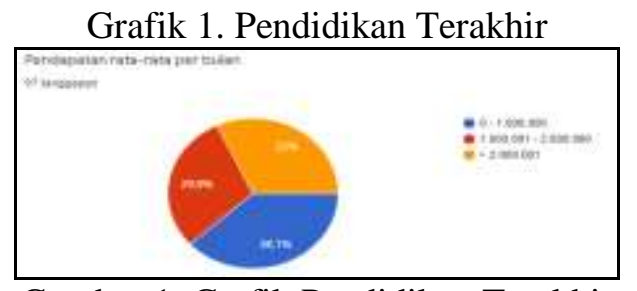

Gambar 1. Grafik Pendidikan Terakhir

Berdasarkan grafik 1. diperoleh hasil bahwa pendapatan rata-rata per bulan responden yang berwisata ke pantai Parangtritis 
Yogyakarta adalah pendapatan 0-1.000.000 sebanyak 37 orang atau $38,1 \%$; pendapatan rata-rata perbulan $\mathrm{Rp}$. 1.000.001,00 sampai dengan Rp. 2.000.000,00 sebanyak 29 orang atau $29,9 \%$ dan pendapatan rata-rata $>2.000 .001$ sebanyak 31 orang atau $32 \%$. .

\section{Uji Validitas dan Reliabilitas}

Cronbach"s Alpha dan corrected item-total correlation digunakan untuk menguji validitas dari indikator dimana indikator dinyatakan valid bila nilai corrected item-total correlation $>\mathrm{r}$ tabel (Ghozali, 2012). Nilai $\mathrm{r}$ tabel diperoleh dengan rumus $\mathrm{df}=\mathrm{n}-2$; dimana $\mathrm{n}=$ jumlah anggota sampel yaitu 97 responden dan taraf signifikasi Alpha $\alpha$ 5\% untuk uji satu arah, sehingga dapat diperoleh nilai $r$ tabel $\mathrm{df}=97$ yaitu 0.1663 .

Sedang untuk uji reliabilitas menggunakan pengukuran sekali saja yang kemudian hasilnya dibandingkan dengan pertanyaan lain atau mengukur reliabilitas dengan uji statistik Cronbach Alpha. Reliabilitas kurang dari 0.6 adalah kurang baik, sedang 0.7 dapat diterima dan diatas 0.8 dinyatakan baik (Ghozali, 2012).

Tabel 4. Uji Validitas dan Reliabilitas

\begin{tabular}{|c|c|c|c|}
\hline Butir & $\begin{array}{c}\text { Corrected } \\
\text { item- Total } \\
\text { Correlation }\end{array}$ & r Tabel & $\begin{array}{c}\text { Keterang } \\
\text { an }\end{array}$ \\
\hline \multicolumn{4}{|c|}{ Social Media } \\
\hline IC 1 & 0.671 & 0.1663 & Valid \\
\hline IC 2 & 0.708 & 0.1663 & Valid \\
\hline IC 3 & 0.715 & 0.1663 & Valid \\
\hline EA 1 & 0.566 & 0.1663 & Valid \\
\hline EA 2 & 0.654 & 0.1663 & Valid \\
\hline EA 3 & 0.558 & 0.1663 & Valid \\
\hline EU 1 & 0.474 & 0.1663 & Valid \\
\hline EU 2 & 0.414 & 0.1663 & Valid \\
\hline EU 3 & 0.558 & 0.1663 & Valid \\
\hline \multicolumn{5}{|c|}{ Brand Image } \\
\hline DTD 1 & 0.473 & 0.1663 & Valid \\
\hline DTD 2 & 0.437 & 0.1663 & Valid \\
\hline DTD 3 & 0.391 & 0.1663 & Valid \\
\hline HTMD 1 & 0.688 & 0.1663 & Valid \\
\hline HTMD 2 & 0.765 & 0.1663 & Valid \\
\hline HTMD 3 & 0.434 & 0.1663 & Valid \\
\hline FD 1 & 0.697 & 0.1663 & Valid \\
\hline FD 2 & 0.755 & 0.1663 & Valid \\
\hline FD 3 & 0.573 & 0.1663 & Valid \\
\hline KD 1 & 0.494 & 0.1663 & Valid \\
\hline
\end{tabular}

\begin{tabular}{|c|c|c|c|}
\hline KD 2 & 0.411 & 0.1663 & Valid \\
\hline KD 3 & 0.608 & 0.1663 & Valid \\
\hline \multicolumn{4}{|c|}{ Buying Interest } \\
\hline TI 1 & 0.583 & 0.1663 & Valid \\
\hline TI 2 & 0.583 & 0.1663 & Valid \\
\hline EI 1 & 0.580 & 0.1663 & Valid \\
\hline EI 2 & 0.580 & 0.1663 & Valid \\
\hline \multicolumn{5}{|c|}{ Purchase Decision } \\
\hline IMP 1 & 0.638 & 0.1663 & Valid \\
\hline IMP 2 & 0.695 & 0.1663 & Valid \\
\hline IMP 3 & 0.600 & 0.1663 & Valid \\
\hline H 1 & 0.732 & 0.1663 & Valid \\
\hline H 2 & 0.714 & 0.1663 & Valid \\
\hline H 3 & 0.723 & 0.1663 & Valid \\
\hline R 1 & 0.706 & 0.1663 & Valid \\
\hline R 2 & 0.734 & 0.1663 & Valid \\
\hline R 3 & 0.744 & 0.1663 & Valid \\
\hline
\end{tabular}

Sumber: Data Primer diolah

Berdasarkan tabel 4. diperoleh hasil bahwa variabel social media, brand image, buying interest dan purchase decision dinyatakan valid.

Tabel 5. Uji Reliabilitas

\begin{tabular}{|c|c|c|}
\hline Variabel & Cronbach's alpha & Keterangan \\
\hline $\begin{array}{l}\text { Social Media } \\
\text { (IC) }\end{array}$ & 0.834 & Reliabel \\
\hline $\begin{array}{l}\text { Social Media } \\
\text { (EA) }\end{array}$ & 0.756 & Reliabel \\
\hline $\begin{array}{l}\text { Social Media } \\
(\text { EU) }\end{array}$ & 0.667 & Reliabel \\
\hline $\begin{array}{l}\text { Brand Image } \\
\text { (DTD) }\end{array}$ & 0.621 & Reliabel \\
\hline $\begin{array}{l}\text { Brand Image } \\
\text { (HTMD) }\end{array}$ & 0.752 & Reliabel \\
\hline $\begin{array}{l}\text { Brand Image } \\
\text { (FD) }\end{array}$ & 0.831 & Reliabel \\
\hline $\begin{array}{l}\text { Brand Image } \\
(\mathrm{KD})\end{array}$ & 0.685 & Reliabel \\
\hline $\begin{array}{l}\text { Buying Interest } \\
\text { (TI) }\end{array}$ & 0.736 & Reliabel \\
\hline $\begin{array}{l}\text { Buying Interest } \\
\text { (EI) }\end{array}$ & 0.734 & Reliabel \\
\hline $\begin{array}{c}\text { Purchase } \\
\text { Decision (IMP) }\end{array}$ & 0.798 & Reliabel \\
\hline $\begin{array}{c}\text { Purchase } \\
\text { Decision }(\mathrm{H})\end{array}$ & 0.852 & Reliabel \\
\hline $\begin{array}{c}\text { Purchase } \\
\text { Decision (R) }\end{array}$ & 0.856 & Reliabel \\
\hline
\end{tabular}

Sumber: Data Primer diolah

Berdasarkan tabel 5. diperoleh hasil bahwa variabel social media, brand image, buying interest dan purchase decision dinyatakan reliabel. 


\section{Uji Model Fit (Analisis Inferensial)}

Hasil nilai Estimated Model pada uji kecocokan model Standardized Root Mean Square Residual (SRMR) menilai besarnya rata-rata perbedaan antara korelasi yang diamati dan yang diharapkan. Nilai hasil uji yang tertera pada tabel diatas adalah sebesar 0.099 kurang dari 0.10 yang artinya model ini merupakan goodness of fit measure untuk PLS-SEM yang dapat digunakan untuk menghindari misspecificaion model (Henseler et al., 2014)

d_ULS (The Squared Euclidean Distance) dan d_G (The Geodesic Distance) bahwa suatu model penelitian yang baik harus memiliki nilai yang lebih besar dari 0,05 (karena menggunakan confidence interval 95\%). Artinya dengan nilai d_ULS sebesar 0.770 dan d_G 0.354 model pada penelitian ini memiliki distribusi residual yang rendah. Nilai Chi-Square yang baik menunjukkan $X^{2}$ Statistik $<X^{2}$ Tabel, artinya jumlah variabel manifes dalam model jalur PLS dan jumlah variabel independen dalam model matriks kovarian tercukupi. Hasil model fit untuk chisquare pada penelitian ini sebesar 0.205 artinya lebih kecil $\chi^{2}$ Tabel sebesar 0.552 dengan signifikansi Pvalues 0.05 dan derajat koefisien (DK) sebesar 499. Artinya jumlah variabel manifes dalam model jalur PLS dan jumlah variabel independen dalam model matriks kovarian tercukupi.

Nilai Normal Fit Index (NFI) pada penelitian ini adalah 0.674, dimana semakin mendekati 1 maka semakin baik kecocokannya. NFI merupakan ukuran kesesuaian model sehingga dapat disimpulkan bahwa model ini sedang.

The Root Mean Squared Residual Covariance Matrix of the Outer Model Residual rms Theta) menilai sejauh mana residu model luar berkorelasi. Model yang baik ukurannya harus mendekati nilai nol. Nilai rms Theta pada penelitian ini adalah sebesar 0,270 sehingga dapat dikatakan bahwa model pengukuran dalam penelitian ini model yang baik, dimana nilai yang semakin mendekati nol maka semakin baik. Nilai rms Theta dibawah 0,12 mengindikasikan model yang paling pas (Henseler et al., 2014).

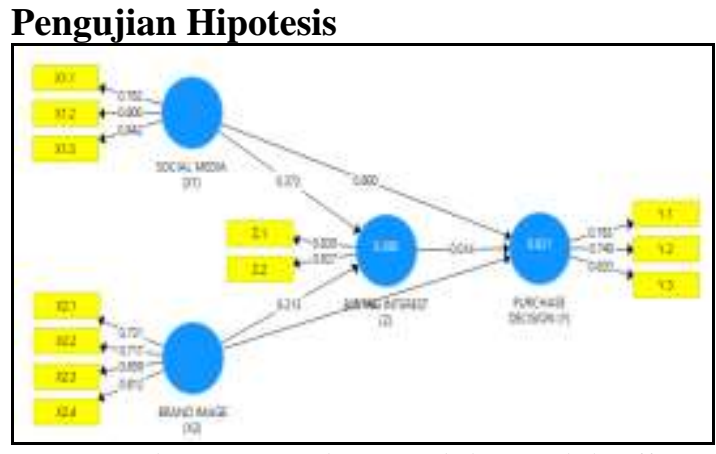

Gambar 2. Gambar model sesudah uji indikator

Hasil uji hipotesis menggunakan smartPLS-3 terhadap model penelitian setelah uji indikator PLS algorith diperoleh pembuktian hipotesis sebagai berikut:

1. Hubungan antara variabel bebas social media (X1) terhadap variabel terikat purchase decision (Y) memiliki nilai pengaruh koefisien positif sebesar 0.800 dan memiliki pengaruh yang signifikan dengan ditunjukkannya nilai $\mathrm{P}$ values yang kurang dari 0.05 yaitu sebesar 0.000 , sehingga dapat dinyatakan bahwa terdapat hubungan positif dan signifikan antara variabel social media terhadap purchase decision. Hal ini bermakna semakin menarik social media instagram pantai Parangtritis Yogyakarta bagi masyarakat maka akan berdampak pada meningkatnya purchase decision.

2. Hubungan antara variabel bebas social media (X1) terhadap variabel buying interest (Z) memiliki nilai pengaruh koefisien positif sebesar 0.014 dan memiliki pengaruh yang signifikan dengan ditunjukkannya nilai $P$ values yang kurang dari 0.05 yaitu sebesar 0.008 , sehingga dapat dinyatakan bahwa antara variabel social media terhadap buying interest terdapat hubungan positif dan signifikan.

Hal ini bermakna semakin menarik social media instagram pantai Parangtritis Yogyakarta bagi masyarakat maka akan 
berdampak pada meningkatnya buying interest.

3. Hubungan antara variabel bebas brand image (X2) terhadap variabel terikat purchase decision (Y) memiliki nilai pengaruh koefisien positif sebesar 0.142 dan memiliki pengaruh yang signifikan dengan ditunjukkannya nilai $\mathrm{P}$ values yang kurang dari 0.05 yaitu sebesar 0.015, sehingga dapat dinyatakan bahwa antara variabel brand image terhadap purchase decision terdapat hubungan positif dan signifikan. Hal ini bermakna semakin unggul dan menarik brand image di mata masyarakat maka akan berdampak pada meningkatnya purchase decision

4. Hubungan antara variabel bebas brand image (X2) terhadap variabel buying interest (Z) memiliki nilai pengaruh koefisien positif sebesar 0.213 dan memiliki pengaruh yang tidak signifikan dengan ditunjukkannya nilai $\mathrm{P}$ values yang lebih dari 0.05 yaitu sebesar 0.129, sehingga dapat dinyatakan bahwa antara variabel brand image terhadap buying interest terdapat hubungan positif namun tidak signifikan. Hal ini bermakna semakin unggul dan menarik brand image yang dipunyai pantai Parangtritis Yogyakarta bagi masyarakat maka akan berdampak pada meningkatnya buying interest

5. Hubungan antara variabel buying interest (Z) terhadap variabel purchase decision (Y) memiliki nilai pengaruh koefisien positif sebesar 0.014 dan memiliki pengaruh yang tidak signifikan dengan ditunjukkannya nilai $\mathrm{P}$ values lebih dari 0.05 yaitu sebesar 0.764 , sehingga dapat dinyatakan bahwa antara variabel buying interest terhadap purchase decision terdapat hubungan positif namun tidak signifikan. Buying interest yang muncul pada masyarakat yang berwisata terbukti memberikan pengaruh yang baik terhadap purchase decision pada masyarakat yang berwisata di pantai Parangtritis Yogyakarta meskipun pengaruh tersebut tidak signifikan.

\section{Uji Sobel(Sobel Test)}

Untuk mengetahui apakah variabel mediasi mampu berperan sebagai mediator antara variabel independen dan variabel dependen maka penelitian ini dilakukan uji sobel tes dengan hasil seperti pada tabel dibawah ini :

Tabel 6. Uji Sobel

\begin{tabular}{|c|l|l|l|}
\hline Variabel & Zskor & Ztabel & Kesimpulan \\
\hline Social Media & 2,66 & 1,96 & $\begin{array}{l}\text { Intervening } \\
\text { berperan }\end{array}$ \\
\hline Brand Image & 1,08 & 1,96 & $\begin{array}{l}\text { Intervening } \\
\text { tidak berperan }\end{array}$ \\
\hline
\end{tabular}

Sumber: Data Primer diolah

Berdasarkan tabel diatas dapat disimpulkan bahwa :

1. Hasil sobel tes menunjukkan bahwa variabel social media memiliki nilai Zscore $2,66>$ dari Ztabel 1,96. Sehingga dapat disimpulkan bahwa variabel buying interest berperan dalam hubungan variabel antara social media dan variabel purchase decision. Ini artinya semakin baik dan menarik social media instagram pantai Parangtritis Yogya maka purchase decision semakin meningkat. Buying interest menjadi mediasi mampu memberikan dampak positif terhadap hubungan social media dan purchase decision.

2. Hasil sobel tes menunjukkan bahwa variabel brand image memiliki nilai Zscore $1.08<$ dari Ztabel 1,96. Sehingga dapat disimpulkan bahwa variabel buying interest tidak berperan dalam hubungan variabel antara brand image dan variabel purchase decision. Semakin menarik brand image dari pantai Parangtritis Yogyakarta maka tidak akan memberikan dampak terhadap meningkatnya purchase decision. Buying interest menjadi mediasi tidak memberikan dampak positif terhadap hubungan brand image dan purchase decision.

\section{PENUTUP}

Berdasarkan hasil analisis dan pembahasan, penelitian ini dapat disimpulkan bahwa variabel social media berpengaruh positif dan signifikan terhadap purchase decision, variabel brand image berpengaruh positif dan signifikan terhadap purchase decision, variabel social media berpengaruh positif dan signifikan terhadap buying interest, variabel brand image berpengaruh positif namun tidak signifikan terhadap buying interest dan 
variabel buying interest berpengaruh positif namun tidak signifikan terhadap purchase decision. Buying interest sebagai mediasi (intervening) berpengaruh pada hubungan variabel social media dan purchase decision dengan nilai Zscore (2.66) > Ztabel (1.96) dan buying interest sebagai mediasi (intervening) tidak berpengaruh pada hubungan variabel brand image terhadap purchase decision dengan nilai Zscore (1.08) < Ztabel (1.96).

Adapun saran yang dapat diberikan dalam penelitian ini yaitu social media instagram hendaknya lebih banyak mengunggah foto dan video yang menarik tentang pantai Parangtritis Yogya, harga tiket masuk pantai Parangtritis Yogya dengan jelas, informasi terkini yang lebih menarik dan bervariatif dan memposting paket wisata menarik lainnya yang berada dilokasi sekitar pantai Parangtritis Yogya. Sedangkan untuk pihak pengelola pantai Parangtritis Yogya hendaknya meningkatkan penyediaan sarana fasilitas toilet, tempat kebersihan, sarana ibadah yang lebih memadai, penyediaan sarana akomodasi yang berupa penginapan atau homestay dan membuat acara menarik di setiap harinya seperti acara perlombaan layang-layang, perlombaan membangun istana pasir dan lain-lainnya sehingga bisa menimbulkan pengalaman yang berkesan bagi masyarakat yang berwisata ke pantai Parangtritis Yogyakarta.

\section{REFERENSI}

Alexi, M., Zulkarnain, Z., \& Musfar, T. (2017). Pengaruh Brand Image Dan Product Design Terhadap Purchase Decision Dan Repurchase Intention Pada Produk Sepatu Futsal Merek Specs Di Kota Pekanbaru. Jurnal Online Mahasiswa Fakultas Ekonomi Universitas Riau, 4(1 Februari 2017), 350-363. Retrieved from https://jom.unri.ac.id/index.php/JOMFE KON/article/view/12680

Amalia, E., \& Sunarti, S. (2019). Pengaruh Media Sosial Terhadap Minat Berkunjung Followers (Survei Pada Followers Akun Instagram @ batuflowergarden.Cobanrais). Jurnal
Administrasi Bisnis (JAB)|Vol, 70(1 Mei 2019), 11-18. Retrieved from http://administrasibisnis.studentjournal.u b.ac.id/index.php/jab/article/view/2809

Caecilia, P. meliani, Kindangen, P., \& Tumewu, F. (2017). The Effect Of Maybelline Social Media Marketing On Consumer Purchase Decision. Jurnal Riset Ekonomi, Manajemen, Bisnis Dan Akutansi, 7(2 September 2017), 232256.

https://doi.org/10.13658/j.cnki.sar.2019. 01.013

Daga, R. (2019). Potensi media sosial sebagai media promosi pariwisata sangatlah besar.

Dejan, A. A. (2018). Pengembangan Objek Wisata Pantai Parangtritis dalam Perspektif Sustainable Development. Government Affairs and Administration, 5(5 Mei 2018). Retrieved from https://www.researchgate.net/publication /325285193_PENGEMBANGAN_OBJ EK_WISATA_PANTAI_PARANGTRI TIS_DALAM_PERSPEKTIF_SUSTAI NABLE_DEVELOPMENT

Edy Susanto, M. (2019). Pengaruh Persepsi Nilai, citra Merek dan Persepsi Harga Terhadap Minat Berkunjung (Studi Kasus pada Jawa Timur Park 3 Kota Wisata Batu). Journal of Chemical Information and Modeling, 53(9 Agustus 2019),

1689-1699. https://doi.org/10.1017/CBO978110741 5324.004

Ghozali, I. (Universitas D. (2012). Aplikasi Analisis Multivariate dengan Program IBM SPSS. Yogyakarta.

Haikal, D. M., \& Suliyanto. (2018). The Effect of Consumer Ethnocentrism , Brand Image , and Perceived Quality, on Purchase Decisions With Purchase Intention as Intervening Variable ( Study of Eiger Consumers in Tasikmalaya ). Journal of Accounting Management and Economics, 20 (2 Juli 2018), 42-45. Retrieved from http://jos.unsoed.ac.id/index.php/jame/ar ticle/view/1120

Hasyyati, R. D. P., \& Khasanah, I. (2019). 
Minat Beli Sebagai Mediasi ( Studi Pada Konsumen Toko Sepatu Bata Semarang ). Diponegoro Journal Of Management, 8(30 Agustus 2019), 1-11. Retrieved from http://ejournals1.undip.ac.id/index.php/djom

Henseler, J., Marko, C. M., \& sarstedt, R. (2014). A new criterion for assessing discriminant validity in variance-based structural equation modeling.

Koesbianto, D. I. (2019). Kabupaten Bantul dalam rangka 2019. Article.

Kotler, P. (2005). Manajemen Pemasaran. Jilid 1 dan 2. Jakarta: PT Indeks Kelompok Gramedia.

Kotler, P., \& Keller, K. L. (2016). Marketing Managemen (15th Editi). Pearson Education,Inc.

Kurniasari, M., \& Budiatmo, A. (2018). Pengaruh Social Media Marketing, Brand Awareness Terhadap Keputusan Pembelian Dengan Minat Beli Sebagai Variabel Intervening Pada J.Co Donuts \& Coffee Semarang. Jurnal Administrasi Bisnis, $7(1 \quad$ Maret 2018), 25. https://doi.org/10.14710/jab.v7i1.22571

Meslat, N. (2018). Impact of social media on ustomers' purchase decision. International Journal of Global Business Management and Research, 5(2 Agustus), 45. https://doi.org/10.14419/ijet.v7i2.30.134 57

Montjai, O., Tewal, B., \& Lengkong, P. . V. (2018). Motivasi, Sikap, Dan Minat Beli Konsumen Pengaruhnya Terhadap Keputusan Pembelian Sepeda Motor Yamaha Pt. Hasjrat Abadi Sentral Yamaha Manado. Emba, 2 (4 Desember 2018), $35-45$. https://doi.org/10.1007/s00253-0081637-5

Mughoffar, M., Sumarwan, U., \& Tinaprilla, N. (2019). The Effect of e-Wom And Brand Image on The Interest in Buying The Heavenly Blush Yoghurt Product. Indonesian Journal of Business and Entrepreneurship, 5(26 Mei), 158-167. https://doi.org/10.17358/ijbe.5.2.158

Nulufi, K., \& Murwatiningsih. (2018). Minat Beli Sebagai Mediasi Pengaruh Brand Image Dan Sikap Konsumen Terhadap
Keputusan Pembelian Batik Di Pekalongan (Studi Kasus pada Konsumen International Batik Center dan Pasar Grosir Setono). Jurnal Manajemen, 4(1 Mei), 1-134. https://doi.org/https://doi.org/10.15294/ maj.v4i2.7813

Nurkarima, N. (2018). Pengaruh Penggunaan Media Sosial Terhadap Akhlakul Karimah dan Akhlakul Madzmumah Siswa Di SMAN 1 Kauman Tahun Ajaran 2017/2018. Institutional Repository, 5(1 Juni), 11. Retrieved from http://repo.iaintulungagung.ac.id/7912/5/Bab II.pdf

Pangestu, M. A. (2018). Pantai Parangtritis Sebagai Destinasi Ikonik di Yogyakarta.

Prasetya, ermawan galih, Yulianto, E., \& Sunarti, S. (2018). Pengaruh Brand Image Terhadap Keputusan Pembelian (Survei Pada Mahasiswa Fakultas Ilmu Administrasi Bisnis Program Studi Administrasi Bisnis angkatan 2018 konsumen Air Mnineral Aqua). Jurnal Administrasi Bisnis, 62(2 september 2018), 214-221. Retrieved from http://administrasibisnis.studentjournal.u b.ac.id/index.php/jab/article/view/2692

Putri, C. S. (2018). Pengaruh Media Sosial Terhadap Keputusan Pembelian Konsumen Cherie Melalui Minat Beli. PERFORMA: Jurnal Manajemen Dan Start-Up Bisnis, 1 (5)(5 Desember 2018), 594. Retrieved from https://journal.uc.ac.id/index.php/perfor $\mathrm{ma} /$ article/view/348

Raheni, C. (2018). Pengaruh Media Sosial Terhadap Minat Beli Konsumen Studi Kasus Mahasiswa The Effect Of Social Media On Consumer Buying Interest Study Case Study. Jurnal Sinar Manajemen, Vol. 5(No. 2), 82-85. Retrieved from https://jurnal.unismuhpalu.ac.id/index.ph p/JSM/article/viewFile/289/175

Rahmawati. (2018). Pengaruh harga dan minat beli terhadap keputusan pembelian konsumen Shopee. Riset Sains Manajemen, 2 (4)(30 November), 143150.

https://doi.org/10.5281/zenodo.1236827

Romadhona, R. N. N., Sudapet, N., \& 
Subagio, H. D. (2018). Influence of Packing Design,Protion and Brand Image on consumer Buying Interest (Study Case of Consumer Glek-Glek Tea Nganjuk). Journal of Intrgrated Edducation,Engineering and Business, 1(2 September), 2615-2312. Retrieved from

https://jurnal.narotama.ac.id/index.php/ij ieeb/article/view/762

Rommy, A. S. N., Moh, N. B. H. H., \& Nur, A. R. Y. N. (2018). Effect Of Brand Image And Price Perception On Purchase Decision. Journal of Business and Management, 20(8 Agustus), 76-81. https://doi.org/10.9790/487X2008027681

Sriyanto, A., \& A.W., K. (2019). Pengaruh Brand Ambassador, Minat Beli , Dan Testimoni Terhadap Keputusan Pembelian (Studi Pada Situs Jual Beli Online Shopee Indonesia di Universitas Budi Luhur Periode Februari -April 2018). Jurnal Ekonomika Dan Manajemen, $8(1 \quad$ April), 21-34. Retrieved from https://journal.budiluhur.ac.id/index.php/ ema/article/view/858

Sudaryanto, S., Subagio, N. A., Awaliyah, I. N., Wulandari, D., \& Hanim, A. (2019). Influence of brand image, price and promotion on consumer's buying decision of fast moving consumer's goods with culture as a moderating variable in basmallah retail store in Indonesia. International Journal of Scientific and Technology Research, 8(3 Maret), 85-92. Retrieved from http://www.ijstr.org/finalprint/mar2019/Influence-Of-BrandImage-Price-And-Promotion-OnConsumers-Buying-Decision-Of-FastMoving-Consumers-Goods-WithCulture-As-A-Moderating-Variable-InBasmallah-Retail-Store-In-Indonesia.pdf Yogesh, F., \& Yesha, M. (2018). Effect of Social Media on Purchase Decision. Pacific Business Review International, 6(11 Mei 2018), 45-51. Retrieved from http://www.pbr.co.in/2018_month/May/ 9.pdf

\section{BIODATA PENULIS}

Sutiyati, S,E. lahir di kampung Kaliberot kelurahan Argomulyo Kecamatan Sedayu Kabupaten Bantul Daerah Istimewa Yogyakarta pada tanggal 26 September 1983. Lulus D-3 Kepariwisataan tahun 2006 dari Universitas Gajah Mada. Lulus S-1 Manajemen pariwista tahun 2013 dari STIE Pariwisata Api Yogyakarta. Lulus kompetensi profesi pendidik tahun 2014 dari Universitas Ahmad Dahlan Yogyakarta. Dan saat ini sedang menempuh S-2 Magister Manajemen di MM UST Yogyakarta. Menjadi staf pengajar (guru) pada kompetensi keahlian Usaha Perjalanan Wisata SMK negeri 1 Sewon Bantul dari tahun 2015 sampai sekarang.

Dr. Ir. Henny Welsa, SE., MM. adalah dosen di Universitas Sarjanawiyata Tamansiswa Yogyakarta di Program Studi Magister Manajemen. Lahir di Palembang pada tanggal 8 Desember 1962. Saat ini yang bersangkutan telah menduduki Jabatan ketua gugus mutu fakultas UST Yogyakarta. Latar belakang pendidikan yang bersangkutan adalah sebagai berikut: 1) Lulus Strata 1 (S1) dari Jurusan pertanian UPN dan Manajemen Universitas Proklamasi Yogyakarta; 2) Menyelesaikan Magister Pendidikan (Strata Dua) dengan gelar Master of Manajemen dari Universitas Islam Indonesia: 3) menyelesaikan S3 dari jurusan Ilmu Ekonomi di Universitas 17 Agustus Surabaya.

Dr. Ambar Lukitaningsih, S.E., MM. adalah dosen di Universitas Sarjanawiyata Tamansiswa Yogyakarta di Program Studi Magister Manajemen. Lahir di Yogyakarta pada tanggal 17 Mei 1965. Saat ini yang bersangkutan telah menduduki Jabatan ketua Program Studi MM UST Yogyakarta. Latar belakang pendidikan yang bersangkutan adalah sebagai berikut: 1) Lulus Strata 1 (S1) dari STIE Jayanegara Malang; 2) Menyelesaikan Magister Pendidikan (Strata Dua) dan S3 dari Universitas Islam Indonesia. 